\title{
The simplex optimization for high porous carbons preparation
}

\author{
J. Sreńscek-Nazzal*, B. Michalkiewicz \\ West Pomeranian University of Technology, Szczecin, Institute of Chemical and Environment Engineering, 70-322 Szczecin, \\ ul.Putaskiego 10, Poland, e-mail: beata.michalkiewicz@zut.edu.pl, jsrenscek@zut.edu.pl \\ *Corresponding author: jsrenscek@zut.edu.pl
}

\begin{abstract}
The microporous carbon materials were prepared by chemical activation of Polish coal with potassium hydroxide using the simplex design method for planning the experiments. The experimental parameters were varied to identify the optimum conditions. Coal can be an excellent starting material for the preparation of high porous carbons for natural gas storage. The porosity of the resultant carbons was characterized by nitrogen adsorption $\left(-196^{\circ} \mathrm{C}\right)$. Methane adsorption was investigated in a volumetric laboratory installation at range pressures from 1 to $3.5 \mathrm{MPa}\left(25^{\circ} \mathrm{C}\right)$.

The best results of methane storage capacity $\left(557 \mathrm{~cm}^{3} \cdot \mathrm{g}^{-1}\right)$ were obtained when using an impregnation ratio 3.41/1 KOH/precursor and temperature at $592^{\circ} \mathrm{C},\left(\mathrm{S}_{\mathrm{LANG}}=2091 \mathrm{~m}^{2} \cdot \mathrm{g}^{-1}\right)$. The parameters of the preparation of high porosity and high methane adsorption carbon were determined by a fast and simple method.
\end{abstract}

Keywords: porous carbon, chemical activation, simplex method, methane adsorption.

\section{INTRODUCTION}

Natural gas (NG) is a alternative fuel, due to its low price and various environmental advantages. Natural gas is an attractive fuel for vehicles because it is a relatively clean burning fuel compared to gasoline. NG vehicles have the potential to lower polluting emissions, especially in urban areas, where air quality has become a major public health concern. The reductions of harmful tailpipe emissions include: air toxins, such as benzene by up to $100 \%$, smog-forming volatile organic compound by $92 \%$ or more, carbon monoxide by $25 \%$, sulfur dioxide by $83 \%$, nitrogen oxide by $10 \% 1$.

The following different categories are known for natural gas storage: liquefied natural gas (LNG), compressed natural gas $(\mathrm{CNG})$, adsorbed natural gas (ANG) and NGH (natural gas hydrates) ${ }^{2}$. In the case of LNG, the cost of liquefaction, required the special insulated vessels and the potential fire hazard make it unsuitable for the LNG use on a large scale. CNG is commercialized worldwide, but there are difficulties related to its high operating pressure. ANG and NGH are major alternative storage methods. Methane can be stored in wet carbon and this method is also called NGH. Nowadays ANG and NGH is not suitable for on-board storage but this method has been studied and developed. Recently Liu et al. $^{2}$ achieved on the wet carbons volumetric storage capacity equal to $204 \mathrm{~V} / \mathrm{V}$. The authors reached the same fuel storage capacity but the storage pressure was twice lower then CNG.

ANG concerns natural gas storage in porous material (adsorbent) as an adsorbed phase. Activated carbon with its high porosity and high surface area can be utilized as an ANG adsorbent. This option can be an interesting alternative that overcomes the above mentioned problem of CNG. Natural gas adsorption on the adsorbent has the advantage of operating at low pressure and room temperature, allowing the natural gas consumption to be comparable to the conventional petroleum based fuels. However, one of the major problems in the ANG process is the development and evaluation of adsorbents ${ }^{3}$.

Due to the efficiency of the carbons porosity in a methane adsorption process, much effort has been put into the preparation of activated carbon with a large surface area. Such adsorbents guarantee obtaining a high methane storage capacity.

The literature have reported that the activated carbons with high specific surface area and high storage capacity were obtained by using different raw materials. As the precursors, e.g. agricultural waste materials, such as coconut and walnut shells, ${ }^{4,5}$, olive stones ${ }^{6,7}$ and corn $\operatorname{cobs}^{8,9}$, sorghum and wheat ${ }^{10}$ which contain high carbon and low ash content, were used. Moreover, novel adsorbents, such as organic gels were explored for the adsorption of methane ${ }^{11}$.

Several papers have reported that the activated carbons were also obtained from coals ${ }^{1,12-14}$ and petroleum coke $^{15,16}$ and zeolites ${ }^{17,18}$. The zeolites have the relatively high packing densities (compared to activated carbons), but have the lower micropore volumes. Activated carbons are very good adsorbents that present the highest ANG energy densities, and thus have the highest storage capacities $^{1,13,19-20}$. On the carbon adsorbents high values of methane storage at $3.5 \mathrm{MPa}$ were obtained e.g. 195 $\mathrm{V} / \mathrm{V}^{19}, 145 \mathrm{~V} / \mathrm{V}^{1}$ and $158 \mathrm{~V} / \mathrm{V}^{20}$. The ideal adsorbent for natural gas storage would be the one with the limited macropore volume and high adsorption capacity for methane.

In general, the process for the preparation of activated carbons can be divided into two categories: the physical and chemical methods. The physical methods consist in the carbonization of the precursor, followed by the gasification of the resulting char in steam or carbon dioxide $^{21}$. The formation of the porous structure is achieved by an elimination of a large amount of internal carbon mass. The chemical method, is performed by carbonizing the raw material that has been impregnated with a chemical reagent e.g. $\mathrm{ZnCl}_{2}{ }^{6}, 7, \mathrm{H}_{3} \mathrm{PO}_{4}{ }^{14}, \mathrm{NaOH}$ ${ }^{22-23}$ and $\mathrm{KOH}^{3,12,24}$. The chemical process using $\mathrm{KOH}$, $\mathrm{NaOH}$, and $\mathrm{ZnCl}_{2}$ as activation agents, could successfully synthesize the activated carbons with high surface area and developed pore structures ${ }^{6,16,25}$. Therefore, a lot of effort is carried out due to the increase of the surface area and porous structures of activated carbons. 
The $\mathrm{KOH}$ chemical activation is a very effective method for the activated carbons with a controlled pore size distribution and the developed pore structures. On the other hand, there are no investigations into obtaining the porous carbons which we prepared by the use of the simplex method.

In this study, we demonstrate the chemical activation of Polish coal for ANG application with potassium hydroxide $(\mathrm{KOH})$ utilizing the simplex design method for planning the experiments. Various parameters were used to produce activated carbons used for gas adsorption applications.

Different variables such as: the effect of agent / coal ratio, the time of impregnation and temperature of pyrolysis, were evaluated. To the our knowledge the simplex method was not utilized for high porous carbon preparation.

\section{MATERIAL AND METHODS}

\section{Sample preparation}

The precursor for the preparation of microporous carbon materials was coal. The precursor was first crushed and sieved to a particle size below $5 \mathrm{~mm}$, and then milled in a ball mill for 120 minutes. The samples were prepared by chemical activation of the precursor with a saturated $\mathrm{KOH}$ solution, used as the activating agent. The pyrolysis was carried out in a tube furnace for 1 hour in nitrogen flow $(18 \mathrm{l} / \mathrm{min})$. The pyrolyzed samples were washed repeatedly with a $5 \mathrm{M}$ solution of $\mathrm{HCl}$ and then with distilled water until free of chlorine ions. The presence of chlorine ions was verified by silver nitrate solution. The samples were dried at $110^{\circ} \mathrm{C}$ for $12 \mathrm{~h}$.

Two series of experiments were performed: Simplex A and Simplex B. Table 1 shows the initial values of the parameters of the chemical activation such as: the effect of the agent/coal ratio, the time of impregnation and the temperature of pyrolysis, which were changed during the preparation of carbons.

Table 1. The initial values of the parameters of the chemical activation of carbons

\begin{tabular}{|c|c|c|}
\hline Parameter & Value $x_{0 n}$ & $\begin{array}{c}\text { Value of variability } \\
\text { unit }\left(\Delta x_{n}\right)\end{array}$ \\
\hline \multicolumn{3}{|l|}{ Simplex A (1 - 6) } \\
\hline $\begin{array}{l}\text { effect of the agent / coal ratio, } \\
R\left(x_{m 1}\right)\end{array}$ & 3 & $\Delta x_{1}=1$ \\
\hline $\begin{array}{l}\text { time of impregnation } \\
I\left(x_{m 2}\right)\end{array}$ & $2 \mathrm{~h}$ & $\Delta \mathrm{x}_{2}=1 \mathrm{~h}$ \\
\hline $\begin{array}{l}\text { temperature of pyrolysis } \\
\mathrm{T}\left(\mathrm{x}_{\mathrm{m} 3}\right)\end{array}$ & $600^{\circ} \mathrm{C}$ & $\Delta \mathrm{x}_{3}=50^{\circ} \mathrm{C}$ \\
\hline \multicolumn{3}{|l|}{ Simplex B $(1-6)$} \\
\hline $\begin{array}{l}\text { effect of the agent / coal ratio, } \\
\mathrm{R}\left(\mathrm{x}_{\mathrm{m} 1}\right)\end{array}$ & 3 & $\Delta \mathrm{x}_{1}=0.5^{\circ} \mathrm{C}$ \\
\hline $\begin{array}{l}\text { time of impregnation } \\
I\left(x_{m 2}\right)\end{array}$ & $2 \mathrm{~h}$ & $\Delta \mathrm{x}_{2}=0.5 \mathrm{~h}$ \\
\hline $\begin{array}{l}\text { temperature of pyrolysis } \\
T\left(x_{m 3}\right)\end{array}$ & $600^{\circ} \mathrm{C}$ & $\Delta \mathrm{x}_{3}=25^{\circ} \mathrm{C}$ \\
\hline
\end{tabular}

\section{Characterization}

The porous texture characterization of all samples was carried out by physical adsorption of $\mathrm{N}_{2}$ at $-196^{\circ} \mathrm{C}$ using an automatic adsorption system (Quantachrome Instruments Quadrasorb). Before measuring the adsorption of $\mathrm{N}_{2}$, the sample was subjected to degassing for $12 \mathrm{~h}$ at $250^{\circ} \mathrm{C}$ at a final pressure of $10^{-4}$ Torr.

Specific surface areas $\left(\mathrm{S}_{\mathrm{LANG}}\right)$ of the carbon were determined from the Langmuir isotherms equation. The Langmuir isotherm equation was used because the adsorption isotherms showed the course of a type I according to IUPAC classification, and the BET equation for $0.05-0.3 \mathrm{p} / \mathrm{p}_{0}$ was not met. The total pore volumes $\left(\mathrm{V}_{\mathrm{p}}\right)$, micropores $\left(\mathrm{V}_{\text {micro }}\right)$ and mesopores $\left(\mathrm{V}_{\text {meso }}\right)$ were determined using the density functional theory (DFT) method. The total pore volume was estimated from the volume of $\mathrm{N}_{2}$ (as liquid) held at a relative pressure $\left(\mathrm{p} / \mathrm{p}_{0}\right)$ between 0.006 and 0.99 .

Raman spectra were obtained with a Renishaw in via Raman Microscope using $785 \mathrm{~nm}$ Ar line as an excitation source. Raman spectra from 800 to 2000 $\mathrm{cm}_{-1}$ at about $0.5 \mathrm{~cm}_{-1}$ interval were measured for 15 $\mathrm{s}$ in the backscattering geometry with a filtered single monochromator. The mostly used part of carbon Raman spectrum is the region from 1000 to $1800 \mathrm{~cm}^{-1}$. In this region the $\mathrm{G}\left(1540-1600 \mathrm{~cm}^{-1}\right)$ and the $\mathrm{D}(1340-1400$ $\mathrm{cm}^{-1}$ ) peaks can be found. The $\mathrm{G}$ peak related to the vibrations of $\mathrm{sp}^{2}$ aromatic rings; the $\mathrm{D}$ or 'disorder' peak is due to the disorder activated optical zone edge modes of microcrystalline graphic sheets ${ }^{26-27}$. The $G$ and $D$ peaks position and the $\mathrm{I}_{\mathrm{D}} / \mathrm{I}_{\mathrm{G}}$ intensity ratio are widely used for identification of the type of carbons and for characterization of the carbons structure. The obtained Raman spectra of the activated carbon materials were deconvoluted by using the Gaussa - Lorenza function in the region from 800 to $2000 \mathrm{~cm}^{-1}$.

Scanning electron microscope (SEM) was used to investigate the morphology of the samples using a SEM -type JEOL ISM-6100.

\section{Determination of the methane adsorption}

The research of methane storage process was carried out in the individually performed laboratory development installation. Methane was fed from a cylinder via a valve connected to a pressure regulator which allowed to obtain demanded pressure. The samples were placed in a stainless steel cell. The cell with the carbon material was thermostated in an oil bath. The samples were degassed at $160^{\circ} \mathrm{C}$ for 16 hours. The system was then cooled to a temperature of $25^{\circ} \mathrm{C}$. The sorption of methane was conducted under the pressure of 1-3.5 $\mathrm{MPa}$ at $25^{\circ} \mathrm{C}$. Prior to the methane storage tests, the free space of the cell was measured. The amount of adsorbed methane was determined based on the differences between the volume of the gas with and without the sample present in the cell.

\section{Simplex method}

The simplex method allows the optimization of multiple factors affecting a process while limiting the number of experiments required to reach the optimum. The simplex method was developed in 1962 by Spendleya, Hexta i Himsworthea ${ }^{28}$. The basic design is the regular simplex described by the designed matrix

$$
D_{0}=\left[\begin{array}{ccccc}
0 & 0 & 0 & \ldots & 0 \\
p & q & q & \ldots & q \\
q & p & q & \ldots & q \\
\cdots & \cdots & \ldots & \ldots & \\
q & q & q & \ldots & p
\end{array}\right]
$$


where

$$
\begin{aligned}
& \mathrm{p}=1 / \mathrm{k} \sqrt{2}[(\mathrm{k}-1)+\sqrt{k+1}] \\
& \text { and } \\
& \mathrm{q}=1 / \mathrm{k} \sqrt{2}(\sqrt{k+1}-1)
\end{aligned}
$$

The rows of the matrix give the $\mathrm{k}$ co-ordinates of each of the $(k+1)$ vertices of the simplex. The $x_{1}$ point of the $\mathrm{D}_{0}$ matrix is situated at the beginning of the coordinate system.

The regular $\mathrm{D}_{0}$ simplex was modified by Gorskij et al. $^{29}$, in the mode, where the beginning of the coordinate system is in the middle of simplex. For factors in the determinate region, the transition from their natural value to the coded value was applied. This is the matrix A of variables coded values described as

$$
\mathrm{A}=\left[\begin{array}{c}
+\mathrm{k}_{1}+\mathrm{k}_{2}+\mathrm{k}_{3} \ldots+\mathrm{k}_{\mathrm{N}-1}+\mathrm{k}_{\mathrm{N}} \\
-\mathrm{R}_{1}+\mathrm{k}_{2}+\mathrm{k}_{3} \ldots+\mathrm{k}_{\mathrm{N}-1}+\mathrm{k}_{\mathrm{N}} \\
+0_{1}-\mathrm{R}_{2}+\mathrm{k}_{3} \ldots+\mathrm{k}_{\mathrm{N}-1}+\mathrm{k}_{\mathrm{N}} \\
+0_{1}+0_{1}-\mathrm{R}_{3} \ldots+\mathrm{k}_{\mathrm{N}-1}+\mathrm{k}_{\mathrm{N}} \\
\cdots \\
+0_{1}+0_{1}+0_{1} \ldots+\mathrm{k}_{\mathrm{N}-1}+\mathrm{k}_{\mathrm{N}} \\
+0_{1}+0_{1}+0_{1} \ldots+\mathrm{k}_{\mathrm{N}-1}+\mathrm{k}_{\mathrm{N}}
\end{array}\right]
$$

where:

$\mathrm{k}_{\mathrm{n}}=[1 / 2 \mathrm{n}(\mathrm{n}+1)]^{1 / 2}$

and

$\mathrm{Rn}=[\mathrm{n} / 2(\mathrm{n}+1)]^{1 / 2}$

for $\mathrm{n}=1,2, \ldots, \mathrm{N} \quad(\mathrm{n}-$ number of the coefficient matrix $)$

A simplex is a geometric figure that has a number of vertex equal to one more than the number of dimensions in the factor space. If $k$ is the number of dimensions in the factor space, then a simplex is defined by $k+1$ points in that factor space. For optimization of a single factor the figure would be a line, for two factors this would be a triangle and for three factors a tetrahedron. Each vertex represents a set of experimental conditions. Thus, the initial series of experiments corresponds to the vertexes of the fixed simplex (points), which determine the values of the variables $x_{1}, x_{2}$ and $x_{3}$ in these experiments. These vertices are then ranked best to worst based on the responses they provide. The next experimental condition, is determined by reflection of the worst point through the hyperface. This is done for each variable. Replacing the previous worst point with the new point creates a new simplex. This new trial replaces the least favorable trial in the simplex. This leads to a new least favorable response in the simplex that, in turn, leads to another new trial, and so on. At each step you move away from the least favorable conditions. By that the simplex will move steadily towards more favorable conditions.

\section{Calculation method}

The simplex optimization begins with the initial trials. The trial conditions are spread out efficiently. The number of initial trials is equal to the number of control variables plus one. The starting point in this method is the design of the matrix. Matrix A with the calculated values $\mathrm{k}_{\mathrm{n}}$ and $\mathrm{R}_{\mathrm{n}}$ for $\mathrm{N}=3$ is defined as:

$$
\mathrm{A}=\left[\begin{array}{ccc}
0.500 & 0.289 & 0.204 \\
-0.500 & 0.289 & 0.204 \\
0 & -0.578 & 0.204 \\
0 & 0 & -0.612
\end{array}\right]
$$

The initial simplex is used for starting the experiments with $\mathrm{M}(\mathrm{M}=\mathrm{N}+1)$. The corresponding rows and columns of the matrix are given values for each parameter.

The initial values of the experiments were calculated by the formula (8)

$\mathrm{x}_{\mathrm{mn}}=\mathrm{x}_{0 \mathrm{n}}+\Delta \mathrm{x}_{\mathrm{n}} \mathrm{a}_{\mathrm{mn}}$

where:

$x_{m n}$ - the value of the parameter $n$ in the $m$ experiment

$x_{0 n}-$ the initial value of the parameter $n$

$a_{m n}-$ the value from the matrix $A$ in the row $m$ and column $\mathrm{n}$

$\Delta \mathrm{x}_{\mathrm{n}}-$ unit variability of the parameter $\mathrm{n}$

After completing the initial simplex and performing the analysis of these results, the parameters, at which the new $M+1$ experiment will be executed, were calculated. Calculations were performed using the formula (9)

$\mathrm{x}_{\mathrm{M}+1, \mathrm{n}}=\frac{2}{\mathrm{~N}} \sum_{\mathrm{m}=1}^{\mathrm{M}} \mathrm{x}_{\mathrm{mn}}-\mathrm{x}_{\mathrm{jn}}$

where:

$\mathrm{m}=1,2, \ldots, \mathrm{M} \quad(\mathrm{M}=\mathrm{N}+1)$, except $\mathrm{m}=\mathrm{j}$

$\mathrm{x}_{\mathrm{jn}}$ - value unsuccessful of the experiment

After the $(\mathrm{M}+1)$ experiment is done and its best value is evaluated, the experiment with the lowest value is rejected, and then the calculations are repeated in order to determine the parameters for the next experiment $X_{M+2}$.

\section{RESULTS AND DISCUSSION}

Based on the equation (8) the initial values for Simplex A and Simplex B were calculated. The following are sample calculations:

$\mathrm{x}_{11}=3+(1 \cdot 0.5)=3.5$

$x_{12}=2+(1 \cdot 0.289)=2.289$

$x_{13}=600+(50 \cdot 0.204)=610.2$

The further three simplex points were calculated using the same method. The surface areas values of the carbons are shown in Table 2.

Table 2. Parameters and surface areas of the prepared carbons Simplex A

\begin{tabular}{|l|c|c|c|c|c|}
\hline \multirow{2}{*}{$\begin{array}{l}\text { Number of } \\
\text { experiments } \\
(\mathrm{m})\end{array}$} & \multicolumn{3}{|c|}{$\begin{array}{c}\text { Value of } \\
\text { parameters }\end{array}$} & \begin{tabular}{c} 
Response \\
Surface \\
area \\
\cline { 2 - 4 }$\left[\mathrm{m}^{2} \cdot \mathrm{g}^{-1}\right]$
\end{tabular} & $\begin{array}{c}\text { Elimination } \\
\text { of } \\
\text { experiments }\end{array}$ \\
\hline $1(\mathrm{In})$ & 3.50 & 2.28 & 610 & 885 & \\
\hline $2(\mathrm{In})$ & 2.50 & 2.28 & 610 & 688 & 1 elimination \\
\hline $3(\mathrm{In})$ & 3.00 & 1.42 & 610 & 746 & 2 elimination \\
\hline $4(\mathrm{In})$ & 3.00 & 2.00 & 570 & 1564 & \\
\hline 5 & 3.83 & 1.52 & 584 & 1969 & best value \\
\hline 6 & 3.89 & 2.45 & 566 & 1452 & \\
\hline
\end{tabular}

(In) - initial simplex

Based on the surface area the point 2 was rejected, because of the smallest surface area. Then point 5 was calculated by using the equation (9):

$\mathrm{x}_{51}=2 / 3(3.5+3+3)-2.5=3.83$

$x_{52}=2 / 3(2.289+1.422+2)-2.289=1.52$

$x_{53}=2 / 3(610+610+570)-610=583$

The surface area of the sample obtained in experiment 5 was higher than the surface areas of the samples ob- 
tained in experiments 1, 3 and 4. The lowest surface area exhibits the sample prepared in experiment 3 . Therefore point 3 was rejected. Based on the equation (9) experiment 6 was calculated. The value of the specific surface area obtained in experiment 6 was lower than that in experiment 5 . Therefore, the simplex was ended, because the result obtained in experiment 6 was worse than the previous one. The best value of the surface area for the prepared carbons was obtained in experiment 5 and it was equal to $1969 \mathrm{~m}^{2} \cdot \mathrm{g}^{-1}$.

The same procedure was used in Simplex B series. The calculated values of parameters $x_{1}, x_{2}, x_{3}$ and the obtained surface areas are shown in Table 3 .

Table 3. Parameters and surface areas of the prepared carbons Simplex B

\begin{tabular}{|c|c|c|c|c|c|}
\hline \multirow{2}{*}{$\begin{array}{l}\text { Number of } \\
\text { experiments } \\
\text { (m) }\end{array}$} & \multicolumn{3}{|c|}{$\begin{array}{c}\text { Value of } \\
\text { parameters }\end{array}$} & \multirow{2}{*}{$\begin{array}{c}\text { Response } \\
\text { Surface } \\
\text { area } \\
{\left[\mathrm{m}^{2} \cdot \mathrm{g}^{-1}\right]}\end{array}$} & \multirow{2}{*}{$\begin{array}{l}\text { Elimination } \\
\text { of } \\
\text { experiments }\end{array}$} \\
\hline & $x_{m 1}$ & $x_{m 2}$ & $x_{\mathrm{m} 3}$ & & \\
\hline 1 & 3.25 & 2.14 & 605 & 1932 & 3 elimination \\
\hline 2 & 2.75 & 2.14 & 605 & 1622 & 1 elimination \\
\hline 3 & 3.00 & 1.71 & 605 & 1953 & \\
\hline 4 & 3.00 & 2.00 & 585 & 1896 & 2 elimination \\
\hline 5 & 3.41 & 1.75 & 592 & 2091 & $\begin{array}{l}\text { the best } \\
\text { value }\end{array}$ \\
\hline 6 & 3.45 & 1.74 & 617 & 1997 & \\
\hline 7 & 3.33 & 1.33 & 605 & 1896 & \\
\hline
\end{tabular}

In experiment 5 the largest surface area was obtained and it was equal to $2091 \mathrm{~m}^{2} \cdot \mathrm{g}^{-1}$. It was observed that the value of the surface area obtained in experiment 6 was very similar to the value of the surface area obtained in point 5 . The difference in the surface area values in experiment 5 and 6 could have been within the limits of error, so calculation of point 7 was performed. After experiment 7 was done it was found that the surface area value obtained in experiment 7 also decrease. Therefore, the simplex method optimizations could have been ended after experiment 6 .

Table 4. Properties of obtained carbons - Simplex A
Because the highest value of surface area was obtained in Simplex A after small number of steps, Simplex B was performed. Because of that, during the Simplex B preparation, the value of $\Delta x_{n}$ was reduced in half. The best surface area in Simplex B was obtained also after just a few experiments and it was noticed that the resulting surface areas were similar.

Table 4 and 5 show pore the volume and surface area values for carbon materials.

Analyzing the data in Tables 4-5, it could be noticed that the increase of the prepared carbons surface area was connected with the development of micropores. The obtained carbons had highly developed microporous structure that was determined by the large micropore volume (0.2165-0.6575).

Figure 1 shows the values of the micropore volume as a function of the surface area for the obtained carbons. It can be seen that the surface area value is directly proportional to the micropore volume.

The nitrogen adsorption/desorption isotherms are presented in Figures 2-3. One can see that carbon materials are mainly microporous with the small fraction of mesopores. The isotherms are categorized to type

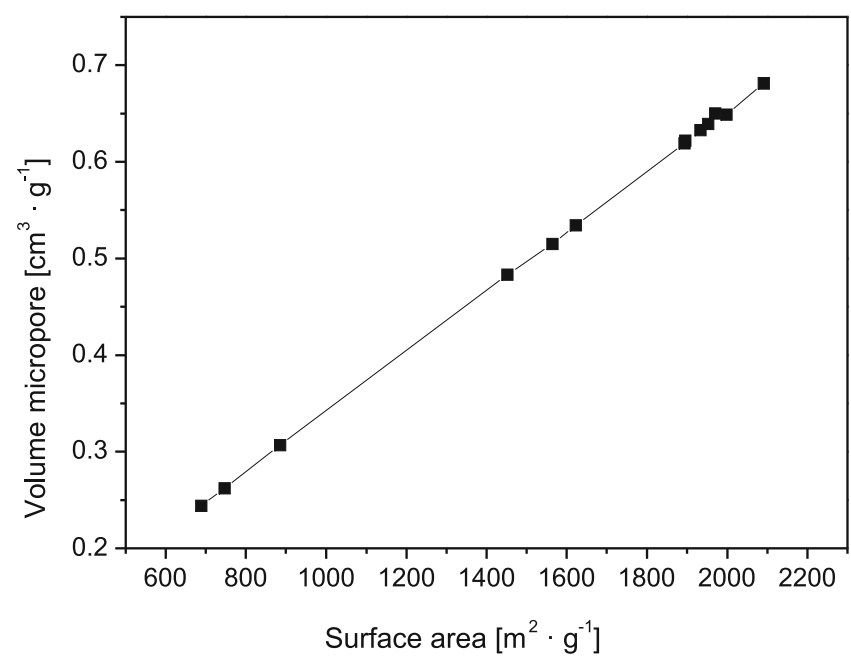

Figure 1. The volume of micropores vs. the surface area of carbon materials

\begin{tabular}{|l|c|c|c|c|c|c|c|}
\hline Sample & $\mathrm{S}_{\text {LANG }}\left[\mathrm{m}^{2} \cdot \mathrm{g}^{-1}\right]$ & $\mathrm{S}_{\text {mikro }}\left[\mathrm{m}^{2} \cdot \mathrm{g}^{-1}\right]$ & $\mathrm{S}_{\text {mezo }}\left[\mathrm{m}^{2} \cdot \mathrm{g}^{-1}\right]$ & $\mathrm{V}_{\text {por }}\left[\mathrm{cm}^{3} \cdot \mathrm{g}^{-1}\right]$ & $\mathrm{V}_{\text {micro }}\left[\mathrm{cm}^{3} \cdot \mathrm{g}^{-1}\right]$ & $\mathrm{V}_{\text {mezo }}\left[\mathrm{cm}^{3} \cdot \mathrm{g}^{-1}\right]$ & $\mathrm{V}_{\text {micro }} / \mathrm{V}_{\text {por }}$ \\
\hline A1 & 885 & 749 & 136 & 0.315 & 0.275 & 0.04 & 0.87 \\
\hline A2 & 688 & 609 & 79 & 0.255 & 0.2165 & 0.0385 & 0.85 \\
\hline A3 & 746 & 674 & 72 & 0.272 & 0.2357 & 0.0363 & 0.87 \\
\hline A4 & 1564 & 1076 & 488 & 0.517 & 0.4895 & 0.0275 & 0.95 \\
\hline A6 & 1970 & 1324 & 649 & 0.656 & 0.6097 & 0.0463 & 0.93 \\
\hline
\end{tabular}

Table 5. Properties of obtained carbons - Simplex B

\begin{tabular}{|l|c|c|c|c|c|c|c|}
\hline Sample & $S_{\text {LANG }}\left[\mathrm{m}^{2} \cdot \mathrm{g}^{-1}\right]$ & $\mathrm{S}_{\text {mikro }}\left[\mathrm{m}^{2} \cdot \mathrm{g}^{-1}\right]$ & $\mathrm{S}_{\text {mezo }}\left[\mathrm{m}^{2} \cdot \mathrm{g}^{-1}\right]$ & $\mathrm{V}_{\text {por }}\left[\mathrm{cm}^{3} \cdot \mathrm{g}^{-1}\right]$ & $\mathrm{V}_{\text {micro }}\left[\mathrm{cm}^{3} \cdot \mathrm{g}^{-1}\right]$ & $\mathrm{V}_{\text {mezo }}\left[\mathrm{cm}^{3} \cdot \mathrm{g}^{-1}\right]$ & $\mathrm{V}_{\text {micro }} / \mathrm{V}_{\text {por }}$ \\
\hline B1 & 1933 & 1338 & 595 & 0.639 & 0.6075 & 0.0315 & 0.95 \\
\hline B2 & 1622 & 1281 & 341 & 0.536 & 0.5128 & 0.0232 & 0.96 \\
\hline B3 & 1953 & 1396 & 557 & 0.641 & 0.6148 & 0.0262 & 0.96 \\
\hline B4 & 1896 & 1366 & 530 & 0.625 & 0.5958 & 0.0292 & 0.95 \\
\hline B5 & 2091 & 1458 & 633 & 0.684 & 0.6575 & 0.0265 & 0.96 \\
\hline B6 & 1998 & 1463 & 535 & 0.649 & 0.6349 & 0.0141 & 0.98 \\
\hline B7 & 1896 & 1338 & 558 & 0.622 & 0.5998 & 0.0222 & 0.96 \\
\hline
\end{tabular}




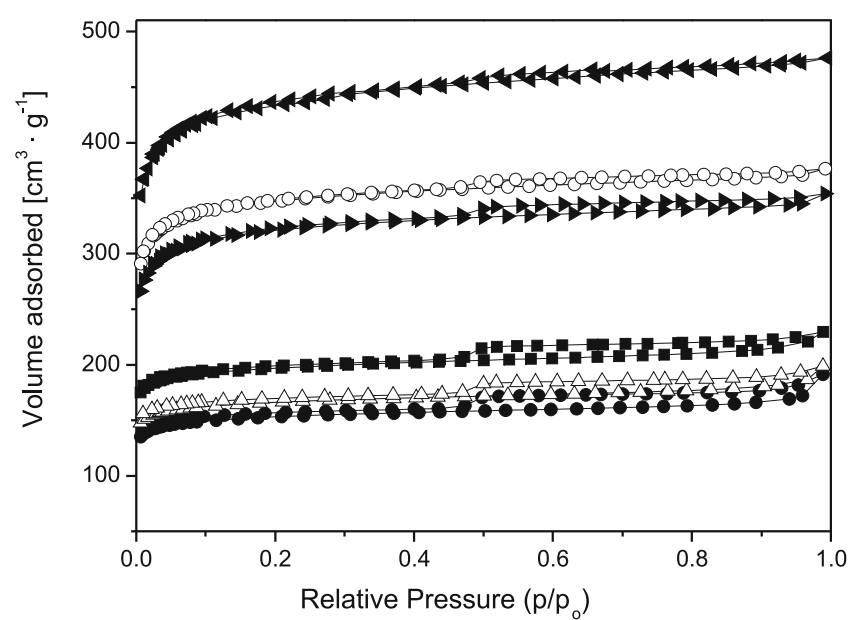

Figure 2. Nitrogen adsorption-desorption isotherms at $77 \mathrm{~K}$ of carbons Simplex A: $\mathbf{\square}-\mathrm{A} 1,-\mathrm{A} 2, \Delta-\mathrm{A} 3$, $\mathrm{O}-\mathrm{A} 4, \boldsymbol{\Delta}-\mathrm{A} 5, \boldsymbol{\nabla}-\mathrm{A} 6$

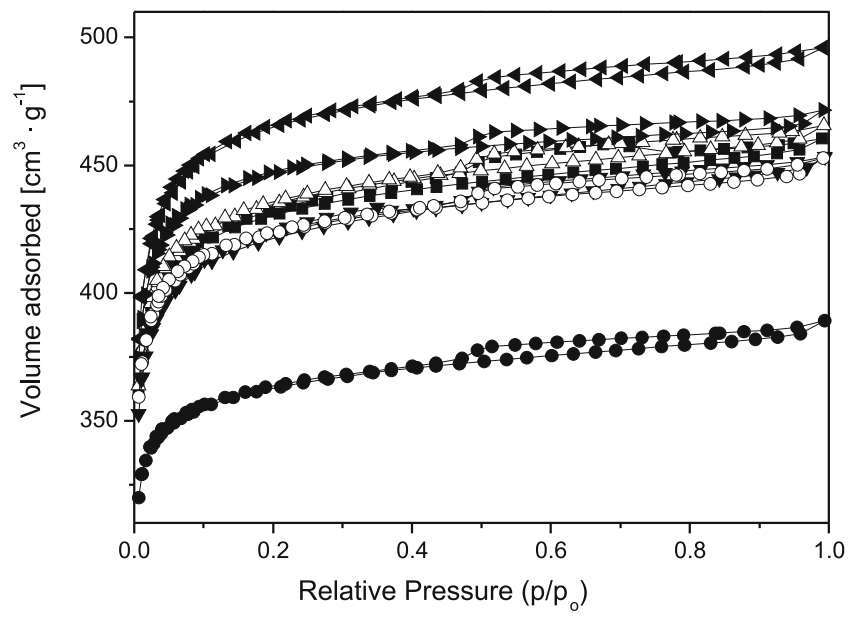

Figure 3. Nitrogen adsorption-desorption isotherms at $77 \mathrm{~K}$ of carbons Simplex B: $\mathbf{\square}-\mathrm{B} 1,-\mathrm{B} 2, \Delta-\mathrm{B} 3$, $\mathrm{O}-\mathrm{B} 4, \mathbf{\Delta}-\mathrm{B} 5, \boldsymbol{\nabla}-\mathrm{B} 6,4-\mathrm{B} 7$

I isotherms by IUPAC classification. The adsorption isotherms are characteristic of porous materials which exhibit a significant amount of micropores. Moreover, in the range of medium and high pressures, the isotherms are nearly parallel to the axis of relative pressures. This indicates that the mesoporosity is not well developed in our samples.

It is also shown in Tables 4 and 5 that the ratio of micropores volume to the total pore volume ranges between $0.85-0.98$. The fraction of micropores in each sample was high.

In order determine the pore size distribution in micropore range, the density functional theory (DFT) was proposed. Carbons A2, A4, and B5 were chosen as typical examples of the lowest, moderate and highest surface area carbons respectively to the presentation of pore distributions determined by DFT method, Raman spectra, SEM micrographs.

Pore - size distribution for the investigated carbons is very similar (Fig. $4-6$ ). The effective micropore volume comprises the pores with diameters ranking from three to six times the molecular size of the adsorbate. Since a methane molecule has a diameter of $0.38 \mathrm{~nm}$, it can penetrate with ease into the pores with the diameters about 1-2 $\mathrm{nm}^{10}$. The obtained diameters of the studied carbons were mostly in that range, which is presented in Figures 4-6. Pores larger than $2 \mathrm{~nm}$ (mesopores

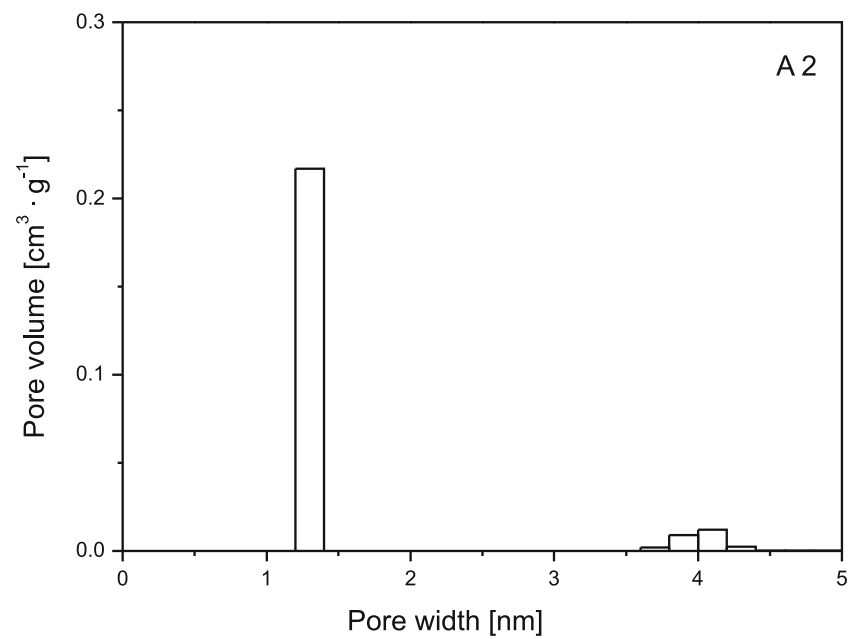

Figure 4. Pore-size distribution of $\mathrm{A} 2$ carbon (KOH:coal ratio 2.5:1, time $2.3 \mathrm{~h}$, temp. $610^{\circ} \mathrm{C}$ )

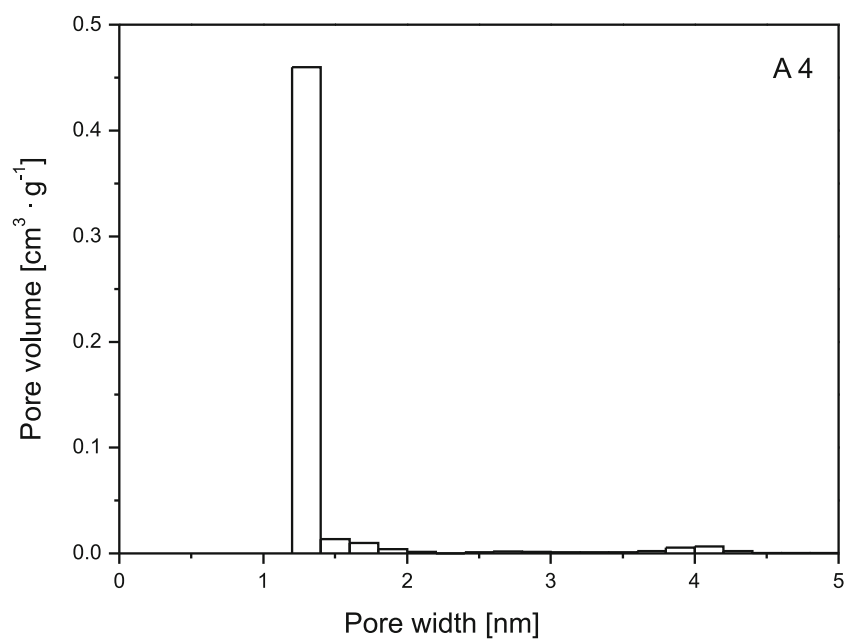

Figure 5. Pore-size distribution of $\mathrm{A} 4$ carbon (KOH:coal ratio 3:1, time $2 \mathrm{~h}$, temp. $570^{\circ} \mathrm{C}$

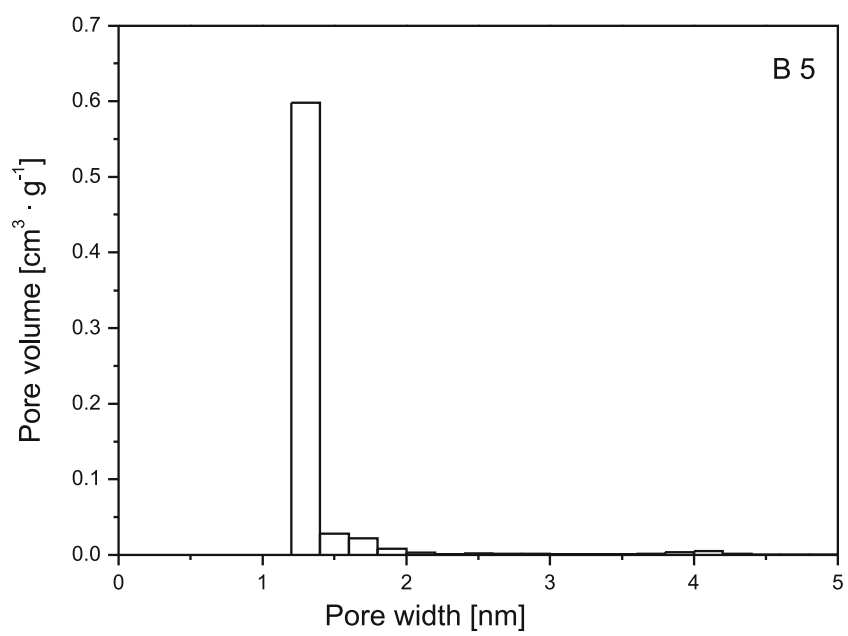

Figure 6. Pore-size distribution of $\mathrm{B} 5$ carbon (KOH:coal ratio 3.4:1, time $1.75 \mathrm{~h}$, temp. $592^{\circ} \mathrm{C}$ )

and macropores) are not used for the methane storage, although they may be needed to transport inside and outside the micropores. Therefore, to increase the methane adsorption storage process the participation of micropores should be maximized.

Raman spectra of active carbon materials obtained in the $800-2000 \mathrm{~cm}^{-1}$ range were subjected to deconvolution using four mixed Gaussian-Lorenzian curves. It is essential to deconvolute the Raman spectra of highly disordered carbon materials in order to acquire the in- 
formation about the skeletal carbon structures in these disordered carbon materials ${ }^{\mathbf{3 0}}$.

The Raman spectra for the all carbon materials were similar (Fig. 7-9). The sharp peaks were observed at about $1580-1593 \mathrm{~cm}^{-1}$ (named G1) and at 1310 to 1330 $\mathrm{cm}^{-1}$ (named D1) and at 1440-1452 $\mathrm{cm}^{-1}$ (named G2) and at $1080-1140 \mathrm{~cm}^{-1}$ (named D2). The D-peaks correspond to the amorphous domains while the G-peaks relate to the graphite domains. Peak at $1582 \mathrm{~cm}^{-1}$ (G band) is attributed to the stretching modes of $\mathrm{C}-\mathrm{C}$ bonds of typical graphite ${ }^{\mathbf{2 6}}$. The peak observed at about $1310-1326 \mathrm{~cm}^{-1}$ was assigned to the D band (related to the defects and disorder in the carbon material) which is typical for disordered carbon.

Table 6 shows the peak intensity ratios of $\mathrm{I}_{\mathrm{D}} / \mathrm{I}_{\mathrm{G}}, \mathrm{I}_{\mathrm{D} 2} /$ $\mathrm{I}_{\mathrm{G} 2}, \mathrm{I}_{\mathrm{G} 2} / \mathrm{I}_{\mathrm{G} 1}$ in the investigated spectrum range, which provides important information about the structure in obtained carbon materials ${ }^{31}$.

The $\mathrm{I}_{\mathrm{D} 1} / \mathrm{I}_{\mathrm{G} 1}$ ratio is very similar for all the tested carbons and ranges between 1.20-1.39. The smaller ratio of $\mathrm{I}_{\mathrm{D} 1} / \mathrm{I}_{\mathrm{G} 1}$ indicates the increase of graphitization degree in the investigated carbon materials ${ }^{\mathbf{3 2}}$. In the A5

Table 6. Characteristics of the structure of carbon materials obtained by the Raman spectra deconvolution

\begin{tabular}{|l|c|c|c|c|}
\hline \multirow{2}{*}{ Carbon } & \multicolumn{3}{|c|}{ Intensity ratio } & \multirow{2}{*}{$\mathrm{L}_{\mathrm{a}}$} \\
\cline { 2 - 4 } & $\mathrm{I}_{\mathrm{D} 1} / \mathrm{I}_{\mathrm{G} 1}$ & $\mathrm{I}_{\mathrm{D} 2} / \mathrm{I}_{\mathrm{G} 2}$ & $\mathrm{I}_{\mathrm{G} 2} / \mathrm{I}_{\mathrm{G} 1}$ & \\
\hline 1 & 1.38 & 0.86 & 0.68 & 3.19 \\
\hline 2 & 1.31 & 0.50 & 0.77 & 3.36 \\
\hline 3 & 1.34 & 0.40 & 0.78 & 3.28 \\
\hline 4 & 1.39 & 0.48 & 0.79 & 3.17 \\
\hline 5 & 1.22 & 0.39 & 0.83 & 3.61 \\
\hline 6 & 1.24 & 0.47 & 0.67 & 3.55 \\
\hline \multicolumn{5}{|c|}{ Simplex A } \\
\hline 1 & 1.27 & 0.53 & 0.76 & 3.46 \\
\hline 2 & 1.33 & 0.58 & 0.75 & 3.31 \\
\hline 3 & 1.29 & 0.57 & 0.78 & 3.41 \\
\hline 4 & 1.28 & 0.51 & 0.85 & 3.44 \\
\hline 5 & 1.20 & 0.44 & 0.87 & 3.67 \\
\hline 6 & 1.31 & 0.48 & 0.79 & 3.36 \\
\hline 7 & 1.32 & 0.58 & 0.80 & 3.33 \\
\hline
\end{tabular}

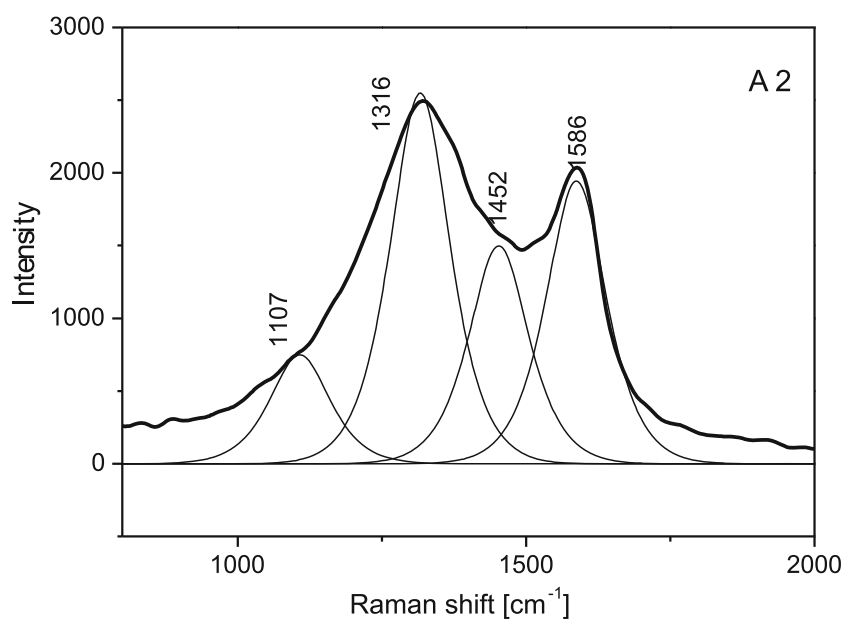

Figure 7. Raman spectra of $\mathrm{A} 2$ carbon (KOH:coal ratio 2.5:1, time $2.3 \mathrm{~h}$, temp. $610^{\circ} \mathrm{C}$ )

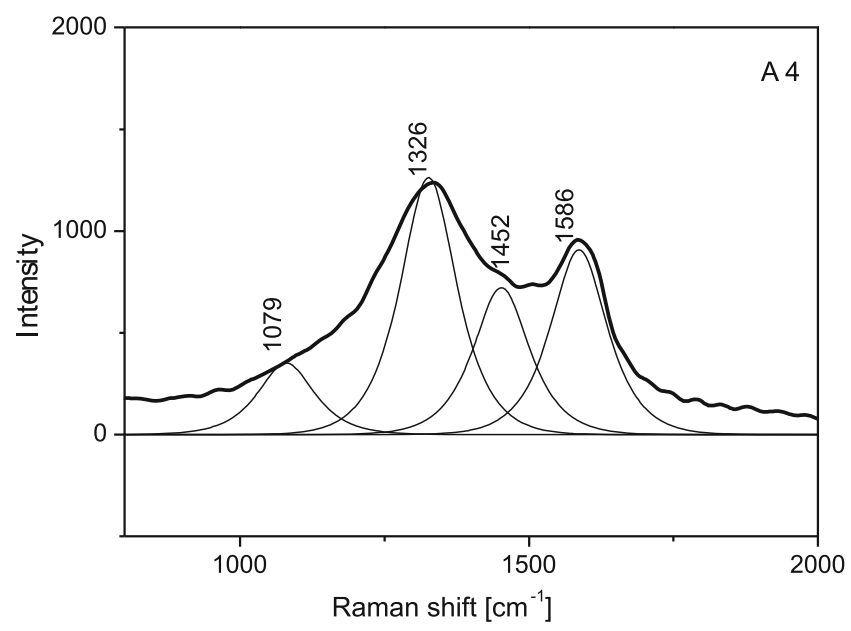

Figure 8. Raman spectra of A4 carbon (KOH:coal ratio 3:1, time $2 \mathrm{~h}$, temp. $570^{\circ} \mathrm{C}$ )

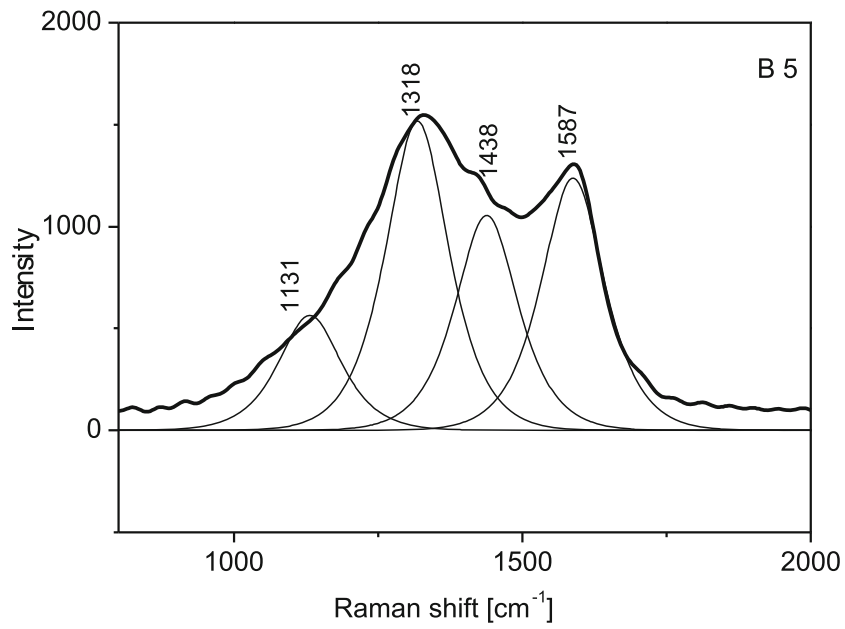

Figure 9. Raman spectra of $\mathrm{B} 5$ carbon (KOH:coal ratio 3.4:1, time $1.75 \mathrm{~h}$, temp. $592^{\circ} \mathrm{C}$ )

and B5 - carbons which have the largest surface area the lowest $\mathrm{I}_{\mathrm{D} 1} / \mathrm{I}_{\mathrm{G} 1}$ ratio was observed. The $\mathrm{A} 5$ and $\mathrm{B} 5$ carbons had the best degree of graphitization. On the basis of formula ${ }^{33}$

$\mathrm{L}_{\mathrm{a}}=4.4 \cdot\left(\mathrm{I}_{\mathrm{D} 1} / \mathrm{I}_{\mathrm{G} 1}\right)^{-1}$

crystalline size was calculated. The $\mathrm{L}_{\mathrm{a}}$ values are listed in Table 6.

It is commonly known that ${ }^{34}$ the lower the $\mathrm{I}_{\mathrm{D} 2} / \mathrm{I}_{\mathrm{G} 2}$ ratio is the less of amorphous phase the carbons contain. The smaller $\mathrm{I}_{\mathrm{G} 2} / \mathrm{I}_{\mathrm{G} 1}$ ratio led to decreasing of the carbon in forms of clusters in the tested materials. According to that it was found that A5 and B5 carbons with the largest surface area contained the least amorphous phase.

Figures 10-12 show an example of the SEM images of carbon materials with the lowest, moderate and highest surface area: carbons A2, A4, and B5

The observations of SEM images allowed the comparison of surface morphology of the studied carbons. Materials that had the smallest surface area such as sample A2 (Fig. 10) presented the most compacted structure of grains. It can be observed that with the increase of the surface $S_{\text {LANG }}$ (Fig. 11-12), the investigated materials had a better porous structure. In the case of carbons with larger surface areas, numerous different sizes empty areas as well as the cavities can be observed. These cavities have irregular shape, however they become bigger with the increase of porosity in the carbon (Fig. 11-12). From the images of carbons with 
Pol. J. Chem. Tech., Vol. 13, No. 4, 2011

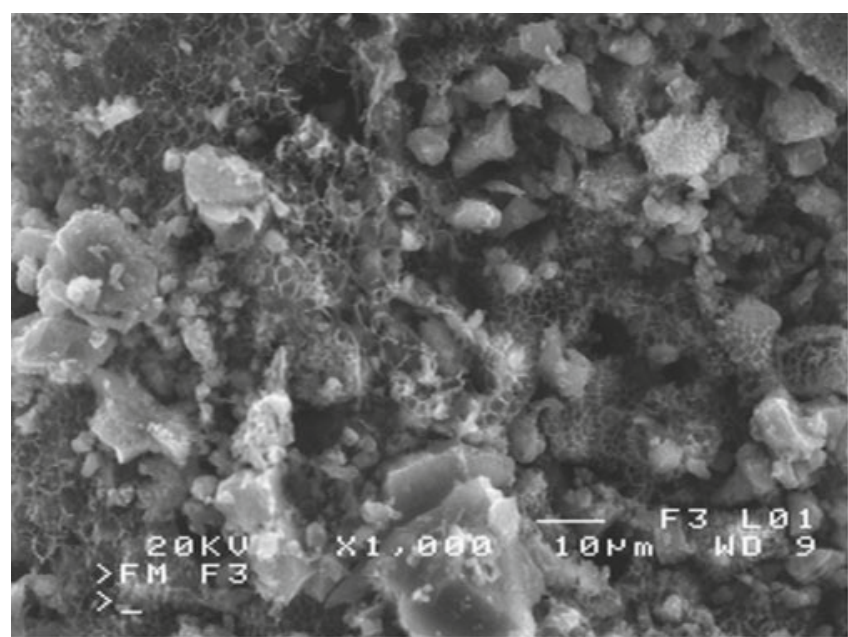

Figure 10. SEM picture of the surface of A2 carbon (KOH:coal ratio $2.5: 1$, time $2.3 \mathrm{~h}$, temp. $610^{\circ} \mathrm{C}$ )

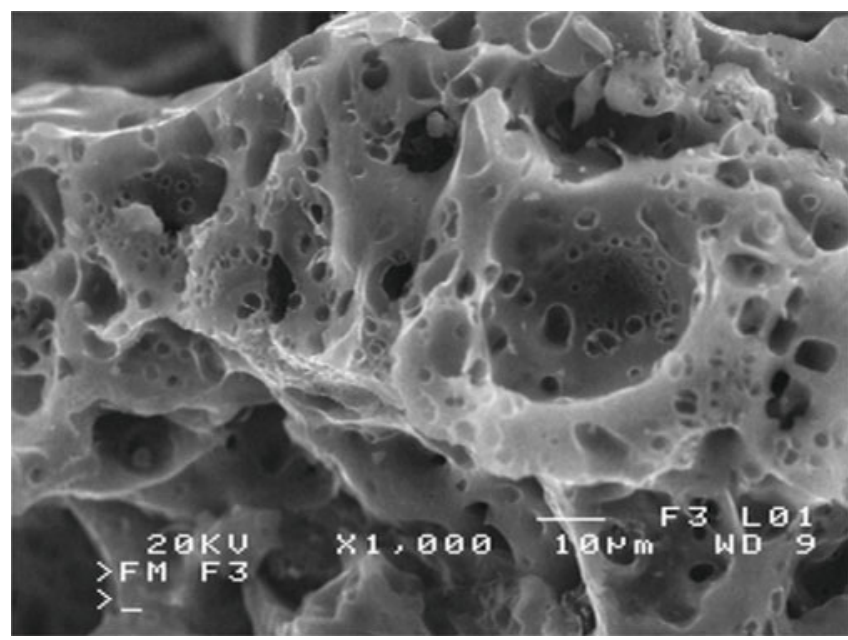

Figure 11. SEM picture of the surface of $\mathrm{A} 4$ carbon (KOH:coal ratio $3: 1$, time $2 \mathrm{~h}$, temp. $570^{\circ} \mathrm{C}$ )

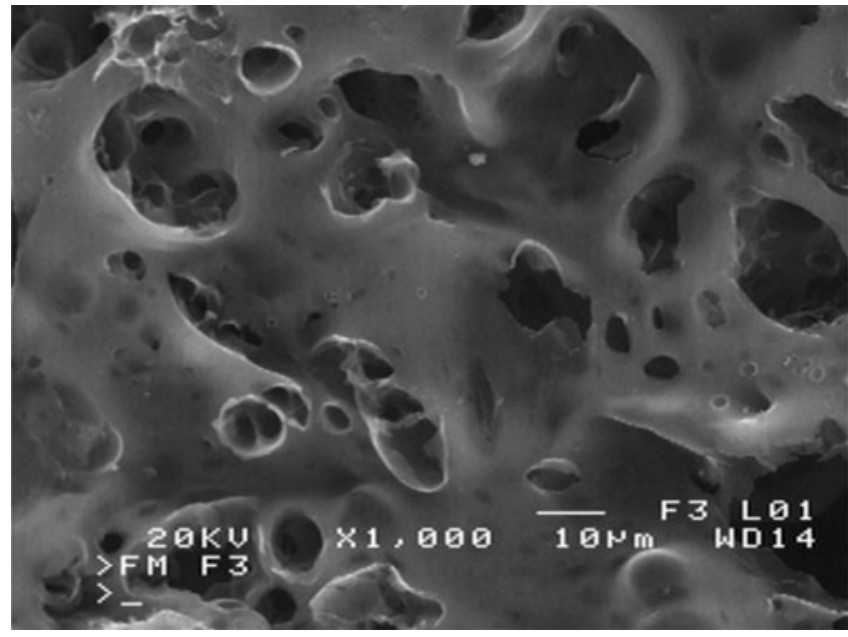

Figure 12. SEM picture of the surface of $\mathrm{B} 5$ carbon (KOH:coal ratio $3.4: 1$, time $1.75 \mathrm{~h}$, temp. $592^{\circ} \mathrm{C}$ )

a large surface area it can be observed that the cavities are deeply embedded in the material. When carefully observing the cavities, it can be suggested that an additional system of canals has been created. It is possible then, that the intensive cavities observed on the carbon surface area are the result of the potassium hydroxide removal from the carbon material.

The carbons were tested in a natural gas adsorption system. The effect of pressure was studied. Four exemplary samples of carbons (A2, A5, A4, B5) are

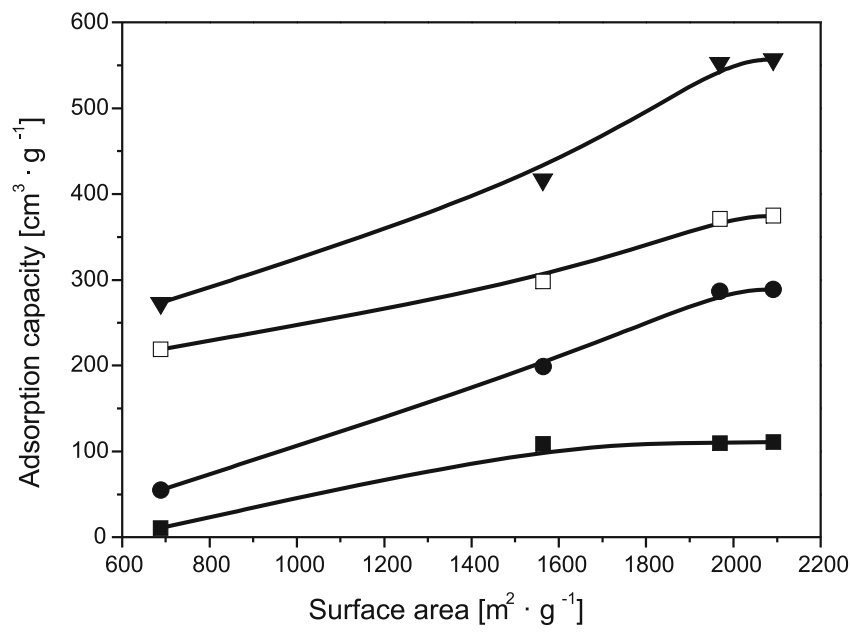

Figure 13. Adsorption capacity of methane vs. the surface area of material: $1 \mathrm{MPa}, 2 \mathrm{MPa}, \square 3 \mathrm{MPa}, \triangle 3.5 \mathrm{MPa}$

presented in Fig. 13.

Two of them (A5, B5) had the largest surface area. In order to compare the sample of small and medium surface area was selected. Figure 13 shows adsorption capacity of methane vs. the surface area of material. The amount of adsorbed methane is presented per unit weight of adsorbent.

It can be seen from Fig 13 that, the natural gas adsorption capacity depends strongly on the $\mathrm{S}_{\text {LANG }}$ specific surface area. The amount of adsorbed natural gas is high at the high specific surface area. As demonstrated earlier, the increase of the surface area is mainly related to the increase of the micropores volume. The increase of micropores amount causes the increase of methane adsorption. To enhance the adsorption storage of methane, the fraction of micropores should be maximized.

\section{CONCLUSIONS}

The carbon materials prepared by chemical activation of Polish coal using potassium hydroxides are mainly microporous. Due to their high surfaces areas (ranging from 688 to $2091 \mathrm{~m}^{2} \cdot \mathrm{g}^{-1}$ ), their low mesopores volumes and their micropore volumes, such materials can be used for methane storage process. It can be concluded that the coal, is a very good starting material for the preparation of carbons. It has to be pointed out that it is a cheap and abundant precursor.

The method proposed in this paper based on simplex minimization allows the simultaneous variation of several variables to obtain the best results in performing of experiments. It produced very satisfactory results in the study of the surface area in the preparation of carbons. Moreover, in the case studied in this paper, only about five experiments were necessary to reach the best surface area.

The great adsorption capacity of methane was obtained utilizing fast and simple method $-557 \mathrm{~cm}^{3} \cdot \mathrm{g}^{-1}$.

\section{LITERATURE CITED}

1. Lozano-Castello, D. Alcaniz-Monge, J. De la Casa-Lillo, M.A. Cazorla-Amoros, D. \& Linares-Solano, A. (2002). Advances in the study of methane storage in porous carbonaceous materials. Fuel 81, 1777-1803. DOI: 10.1016/S00162361(02)00124-2.

2. Liu, J., Zhou, Y., Sun, Y., Su, W. \& Zhou, L. (2011). 
Methane storage in wet carbon of tailored pore sizes. Carbon 49, 3731-3736. DOI: 10.1016/j.carbon.2011.05.005.

3. Lozano-Castello, D., Cazorla-Amoros, D. \& Linares-Solano, A. (2002). Powdered activated carbons and activated carbon fibers for methane storage: A camparative study. Energy Fuels 16, 1321-1328. DOI: 10.1021/ef020084s.

4. Garcia Blanco, A.A., Alexandre de Oliveira, J.C., Lopez, R., Moreno-Pirajan, J.C., Giraldo, L., Zgrablich, G. \& Sapag, K. (2010). A study of the pore size distribution for activated carbon monoliths and their relationship with the storage of methane and hydrogen. Colloids Surf., A 357, 74-83. DOI: 10.1016/j.colsurfa.2010.01.006

5. Zhou, Y., Wang, Y., Chen, H. \& Zhou, L. (2005). Methane storage in wet activated carbon: Studies on the charging/ discharging process. Carbon 43, 2007-2012. DOI: 10.1016/j. carbon.2005.03.017.

6. Rodriguez-Reinoso, F., Nakagawa, Y., Silvestre-Albero, J., Juarez-Galan, J.M. \& Molina-Sabio, M. (2008). Correlation of methane uptake with microporosity and surface area of chemically activated carbons. Microporous Mesoporous Mater. 115, 603-608. DOI: 10.1016/j.micromeso.2008.03.002.

7. Almansa, C., Molina-Sabio, M. \& Rodriguez-Reinoso, F. (2004). Adsorption of methane into $\mathrm{ZnCl} 2$-activated carbon derived discs. Microporous Mesoporous Mater. 76, 185-191. DOI: 10.1016/j.micromeso.2004.08.010.

8. Bagheri, N. \& Abdei, J. (2011). Adsorption of methane on corn cobs based activated carbon. Chem Eng Res Des. Article in Press. DOI: 10.1016/j.cherd.2011.02.002.

9. Abdel-Nasser, A. \& El-Hendawy. (2003). Influence of HNO3 oxidation on the structure and adsorptive properties of corncob-based activated carbon. Carbon 41, 713-722. DOI: 10.1016/S0008-6223(03)00029-0.

10. Zhang, T., Walawender, P.W. \& Fan, L.T. (2010). Grain-based activated carbons for natural gas storage. Bioresour. Technol. 101, 1983-1991. DOI: 10.1016/j.biortech.2009.10.046.

11. Feaver, A. \& Cao, G. (2006). Activated carbon cryogels for low pressure methane storage. Carbon 44, 590-593. DOI:10.1016/j.carbon.2005.10.004.

12. Lozano-Castello, D., Lillo-Rodenas, M.A. Cazorla-Amoros, D. \& Linares-Solano, A. (2001). Preparation of activated carbons from Spanish anthracite I. Activation by KOH. Carbon 39, 741-749. DOI:PII: S0008-6223(00)00185-8.

13. Menon, V.C. \& Komarneni, S. (1998). Porous adsorbents for vehicular natural gas storage. J. Porous Mater. 5, 43-58.

14. Hsu, L. \& Teng, H. (2000). Influence of different chemical reagents on the preparation of activated carbons from bituminous coal. Fuel Process. Technol. 64, 155-166. DOI: PII: S0378- 3820 00.00071-0.

15. Zhang, H., Chen, J. \& Guo, S. (2008). Preparation of natural gas adsorbents from high-sulfur petroleum coke. Fuel 87, 304-311. DOI:10.1016/j.fuel.2007.05.002.

16. Dai, X.D., Liu, X.M., Qiao, L. \& Yan, Z.F. (2008). Pilot Preparation of Activated Carbon for Natural Gas Storage. Energy Fuels 22, 3420-3423.DOI:10.1021/ef800313f.

17. Guan, C., Loo, L.S., Wang, K. \& Yang, C. (2011). Methane storage in carbon pellets prepared via a binderless method. Energy Convers. Manage. 52, 1258-1262. DOI: 10.1016/j. enconman.2010.09.022.

18. Guan, C., Su, F., Zhao, X.S. \& Wang, K. (2008). Methane storage in a template-synthesized carbon. Sep. Purif. Technol. 64, 124-126. DOI:10.1016/j.seppur.2008.08.007.

19. Celzard, A. \& Fierro, V. (2005). Preparing a suitable material designed for methane storage. Energy Fuels. 19, 573-583. DOI: 10.1021/ef040045b.

20. Perrin, A., Celzard, A., Mareche, J.F. \& Furdin, G. (2003). Methane storage within dry and wet active carbons: A comparative study. Energy Fuels 17, 1283-1291. DOI: 10.1021/ ef030067i.

21. Yeon, S-H., Osswald, S., Gogotsi, Y., Singer, J.P., Simmons, J.M., Fischer, J.E., Lillo-Rodenas M.A. \& Linares-Solano A.
(2009). Enhanced methane storage of chemically and physically activated carbide-derived carbon. J. Power Sources 191, 560-567. DOI:10.1016/j.jpowsour.2009.02.019.

22. Perrin, A., Celzad, A., Albiniak, A., Jasienko-Halat, M., Mareche, J.F. \& Furdin, G. (2005). NaOH activation of anthracites: effect of hydroxide content on pore textures and methane storage ability. Microporous Mesoporous Mater. 81, 31-40. DOI:10.1016/j.micromeso.2005.01.015.

23. Lillo-Rodenas, M.A., Lozano-Castello, D., Cazorla-Amoros, D. \& Linares-Solano, A. (2001). Preparation of activated carbons from Spanish anthracite II. Activation by $\mathrm{NaOH}$. Carbon 39, 751-759. PII: S0008-6223(00)00186-X.

24. Tay, T., Ucar, S. \& Karagoz, S. (2009). Preparation and characterization of activated carbon from waste biomass. J. Hazard. Mater., 165, 481-485. DOI: 10.1016/j.jhazmat.2008.10.011.

25. Lozano-Castello, D., Cazorla-Amoros, D., Linares-Solano, A. \& Quinn, D.F. (2002). Influence of pore size distribution on methane storage at relatively low pressure: preparation of activated carbon with optimum pore size. Carbon 40, 989-1002. PII: S0008-6223(01)00235-4.

26. Qiu, J., Li, Y., Wang, Y., Liang, C., Wang, T. \& Wang, D. (2003). A novel form of carbon micro-balls from coal. Carbon 41, 767-772. DOI:10.1016/S0008-6223(02)00392-5.

27. Tuinstra, F. \& Koening, J.L. (1970). Raman spectrum of graphite. J. Chem. Phys. 53 1126-1130.

28. Spendley, W., Hext, G.R. \& Himsworth, F.R. (1962). Sequential application of simplex designs in optimisation and evolutionary operation. Technometerics 4, 441-461.

29. Gorskij, W.G. \& Brodskij, W.Z. (1965). Simplex design method for planning the optimum experiments. Zawod. Lab. 31, 831-836.

30. Veres, M., Fule, M., Toth, S., Koos, M. \& Pocsik, I. (2004). Surface enhanced Raman scattering (SERS) investigation of amorphous carbon. Diamond Relat. Mater. 13, 1412-1415. DOI: 10.1016/j.diamond.2004.01.041.

31. Shimodaira, N. \& Masui, A. (2002). Raman spectroscopic investigations of activated carbon materials. J. Appl. Phys. 92, 902-909.

32. Kumar, R., Tiwari, R.S. \& Srivastava, O.N. (2011). Scalable synthesis of aligned carbon nanotubes bundles using green natural precursor: neem oil. Nanoscale Res. Lett. 92, 1-6. DOI:10.1186/1556-276X-6-92.

33. Zhang, Y., Tang, Y., Lin, L. \& Zhang, E. (2008). Microstructure transformation of carbon nanofibers during graphitization. Trans. Nonferrous Met. Soc. China 18, 1094-1099.

34. Kierzek, K. 2006. Activated carbon materials with potassium hydroxide. PhD Thesis. Wroclaw University of Technology. 